\title{
Muscle wasting in chronic alcoholics: comparative histochemical and biochemical studies
}

\author{
HD LANGOHR, H WIETHÖLTER, J PEIFFER
}

From the Department of Neurology and from the Institute for Brain Research, University of Tübingen, Federal Republic of Germany

SUMMARY The comparative electrophysiologic, histochemical, and biochemical investigation of the anterior tibial muscle of 13 alcoholics indicates that neuropathy could be the cause of the chronic muscle weakness and wasting. Myopathic alterations did not predominate in the findings. It was concluded that the proximal muscle atrophy could also be attributed to neurogenic damage. Histochemical reactions in muscle specimens showed a selective type 2 atrophy and a slight increase of the mean diameter of type 1 fibres. Biochemical investigations revealed that the activities of a number of enzymes representative of energy supplying pathways-the glycogenolysis and glycolysis-as well as acid phosphatase activity in the muscle were lowered. A relationship could be assumed between the lowered glycolytic activity and the decline of the mean diameter of type 2 fibres. Oxidative enzymes were of similar activity in the alcoholics and the control group. The glycolytic enzyme activities were particularly important, being the most sensitive indicators of the onset, intensity, and course of neurogenic damage. These activities probably normalise during reinnervation of a muscle earlier than do the morphologic alterations; however, they were markedly lower in alcoholics with impaired liver function and cachexia, probably because of the catabolic metabolic conditions present in these cases.

Wasting and weakness of the distal and proximal muscles is often observed in chronic alcoholics even though clinical and electrophysiologic examinations show no signs of a serious neuropathy. On the other hand, according to $\mathrm{Oh},{ }^{12}$ alcoholic myopathy occurs in only $0.8 \%$ of all hospitalised alcoholics. Several researchers $^{2-6}$ defined three groups of alcoholic myopathies: an acute syndrome with rhabdomyolysis and myoglobinuria, subacute to chronic forms with proximal atrophy and paresis, and an asymptomatic form with only histopathologic and electromyographic signs of myopathy. A few investigators question whether subacute or chronic weakness of the proximal muscles in alcoholics is really due to primary myopathy..$^{7-9}$ They assume that the histological alterations are produced by the denervation associated with alcoholic neuropathy.

We frequently observed alcoholics with generalised wasting of the distal and proximal muscles and a

Address for reprint requests: Prof Dr HD Langohr, Department of Neurology, University of Tübingen, Liebermeisterstr. 18-20, 7400 Tübingen, Federal Republic of Germany.

Received 25 June 1982

Accepted 30 September 1982 corresponding decrease in vitality. As a rule, only discrete signs of axonal neuropathy, somewhat more pronounced in the distal muscles, were detectable by electromyography. Comparative electrophysiologic, biochemical, and histochemical studies therefore were carried out to determine which method is most sensitive for detecting muscle damage and whether the muscular dysfunction is caused by neuropathy or myopathy.

\section{Patients and methods}

Thirteen patients ( 12 males, 1 female; age, 35-55 yr) with a 10 to 35 year history of alcoholism were studied. Two patients had a history of delirium tremens; two were admitted for epileptic attacks after alcohol withdrawal; four had been treated for alcoholic hepatopathy and were then referred to our outpatient service for clarification of their muscle wasting; two suffered from cerebellar atrophy; and three from head injury. No neuromuscular or other neurological disorders could be found in the history of their families. GOT, GPT, alkaline phosphatase, gamma GT, serum electrophoresis, serum bilirubin, electrolytes, and total serum protein values were determined for all hospitalised patients. Erythrocytic thiamine, riboflavin, and pyridoxine as well as serum folic acid and vitamin $B_{12}$ 
were measured in some of them.

During the neurologic examination, particular attention was given to discrete signs of beginning polyneuropathy, for example weakened ankle jerks, disturbed deep sensibility, slightly impaired superficial sensibility. The percentage of polyphasic potentials of the anterior tibial muscle was determined by electromyography. Distal motor latency and maximal motor nerve conduction velocity of the peroneal nerve were also measured. The form and amplitude of the action potential over the extensor digitorum brevis muscle, evoked by supramaximal stimulation of the peroneal nerve and recorded with bipolar surface electrodes, was given special consideration. Neurogenic damage was assessed according to the criteria cited by Buchthal. ${ }^{10}$ According to the normal limits for our laboratory, nerve conduction velocities below $40 \mathrm{~m} / \mathrm{s}$ were considered pathological. After 8 to 14 days of abstinence, all patients were given a thorough clinical and electrophysiologic examination. Several muscle specimens (50-100 mg) from the anterior tibial muscle were then obtained from each patient. Biopsies were invariably taken from the same site. This was different from the site of insertion of the electromyographic needle which was marked. Activities of representative enzymes involved in the energy-supplying metabolism ${ }^{11-18}$ were measured with biochemical methods in one portion of the tissue specimen. Muscle biopsies from 14 neurologically healthy men and women of approximately the same age served as controls (mean \pm 2 SD). PH, TPDH, LDH, HAD, CS, and 6-PGDH* activities were measured with the method described in an earlier publication. ${ }^{16}$ Hexosephosphate isomerase, ${ }^{19}$ acid phosphatase, and malate dehydrogenase activities were also measured (Monotest/Boehringer). The activities measured were determined for $1 \mathrm{~g}$ wet weight of muscle tissue. In the alcoholics enzyme activities which were below the range of normalcy established for the control group (mean $\pm 2 \mathrm{SD}$ ) were considered pathological.

A second portion of the muscle specimens was subjected to histologic and histochemical studies. One specimen was fixed in buffered paraformaldehyde, embedded in methacrylate, and stained according to van Gieson and with haematoxylin and eosin. Another piece was frozen in isopentane precooled with nitrogen for histochemical preparation. NADH-diaphorase and ATP-ase stain (pH 9.4; $\mathrm{pH} 4.6,4.2$ respectively) were demonstrated on cryostatic cross sections $(6 \mu)$. A modified trichrome and oil-red stain were applied as well. The specimens were also evaluated with histometric methods. Approximately 200 muscle fibres selected at random from each specimen were photographed, enlarged $(\times 140)$, and then measured. Lesser fibre diameters were measured as the distance between the closest parallel lines laid tangential to opposite boundaries of the muscle fibre. ${ }^{20}$ This diameter was recorded in relation to the muscle fibre type as determined by the ATP-ase stain (pH 9.4). The following data were calculated for each biopsy specimen: distribution of

*Abbreviations: APH, acid phosphatase; HAD, $\beta$-hydroxyacyl CoA dehydrogenase; HIM, hexosephosphate isomerase; $\mathrm{LDH}$, lactate dehydrogenase; MDH, malate dehydrogenase; 6-PGDH, 6-phosphogluconate dehydrogenase; $\mathrm{PH}$, total phosphorylase; TPDH, triosephosphate dehydrogenase. type 1 and type 2 fibres expressed in percent, mean diameters and standard deviation of both fibre types, and the coefficient of variability. Data from six healthy individuals and information cited by different investigators served as control values. ${ }^{21-24}$

\section{Results}

All of the 13 patients showed signs of generalised muscle wasting, particularly in the legs. Predominantly sensory polyneuropathy as determined by clinical testing was present in 10 patients. Ankle jerks were diminished or abolished, vibratory sensitivity was defective, and cutaneous sensibility was slightly impaired. Circumscribed paresis was observed in none of the patients. Patients did not complain of muscle weakness until questioned.

As determined by electromyography and electroneurography patients showed signs of discrete to mild axonal polyneuropathy. The percentage of polyphasic potentials was elevated and the recruitment of motor units on maximal innervation, decreased. The maximal conduction velocity of the peroneal nerve was below $40 \mathrm{~m} / \mathrm{s}$ in only one patient and within the normal range in the rest. None of our patients showed an evoked muscle action potential over the extensor digitorum brevis muscle below 3 $\mathrm{mV}$.

Most of the patients showed type 2 atrophy on the standard ATP-ase and NADH-diaphorase reaction (fig 1). Angular fibres, target fibres and type grouping indicating chronic denervation were frequently observed. No degenerative fibre alterations were detected that would support the predominance of a myopathy. Figure 2 shows the histogram for the diameters of muscle fibres from the anterior tibial in a normal and an alcoholic. There is an average decrease in type 2 fibres in the chronic alcoholic. The mean diameter of type 2 fibres in the normal anterior tibial muscle was $82.7 \pm 12.4 \mu \mathrm{m}$. The mean diameter of type 2 fibres of the muscles most frequently biopsied (that is vastus lateralis and gastrocnemius) ranged between 35 and $75 \mu \mathrm{m}$. Type 2 fibres were markedly atrophied in alcoholics. Their mean diameter shifted to the left $(60 \cdot 2 \pm 5 \cdot 2)$. At the same time, the mean diameter of type 1 fibres increased $(59.9 \pm 9.4)$. The percentage of type 1 fibres was considerably higher than that of type 2 fibres both in normals (type $1,73 \%$; type $2,27 \%$ ) and in alcoholics $(72 / 28 \%)$.

The average data from both groups investigated are presented in the table. The decrease in mean diameter of type 2 fibres and the increase in mean diameter of type 1 fibres in chronic alcoholics is best described by the quotient obtained when the mean diameter of type 2 fibres is divided by the mean 

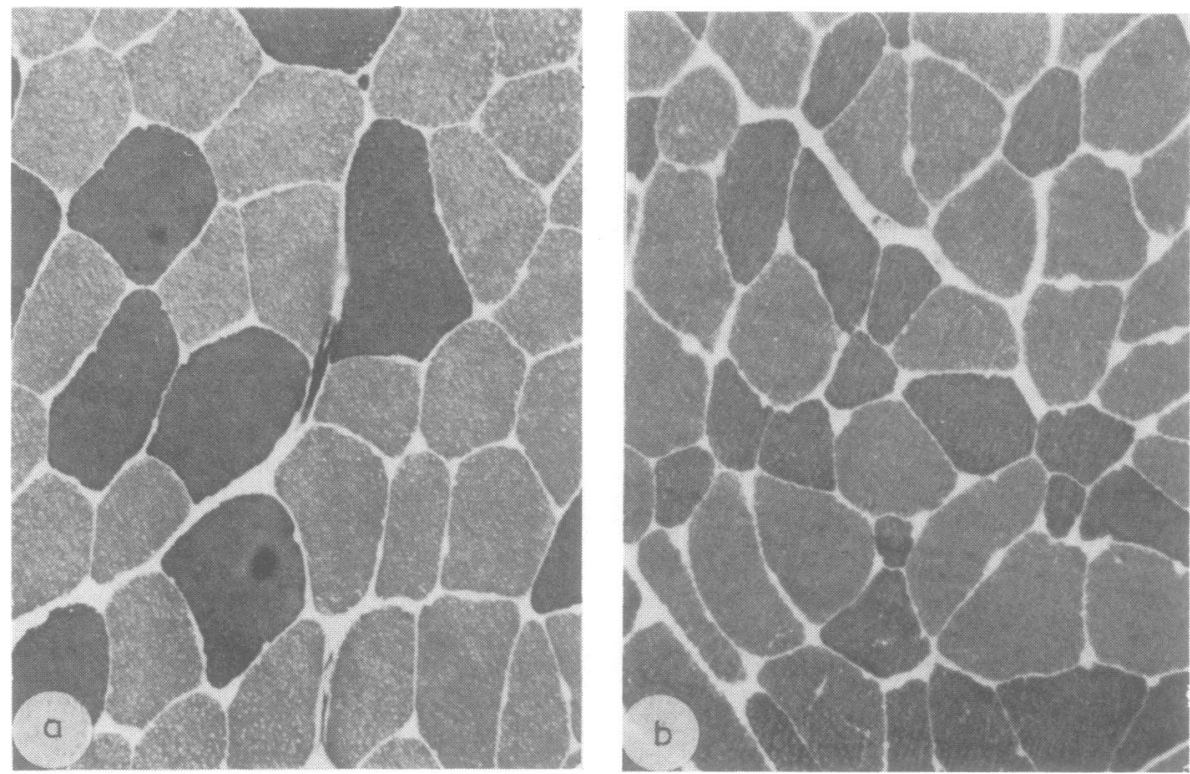

Fig 1 (a) Cross section of normal anterior tibial muscle. (b) Cross section of anterior tibial muscle from an alcoholic:atrophy of type 2 fibres. ATPase stain, pH $9.4(\times 140)$.

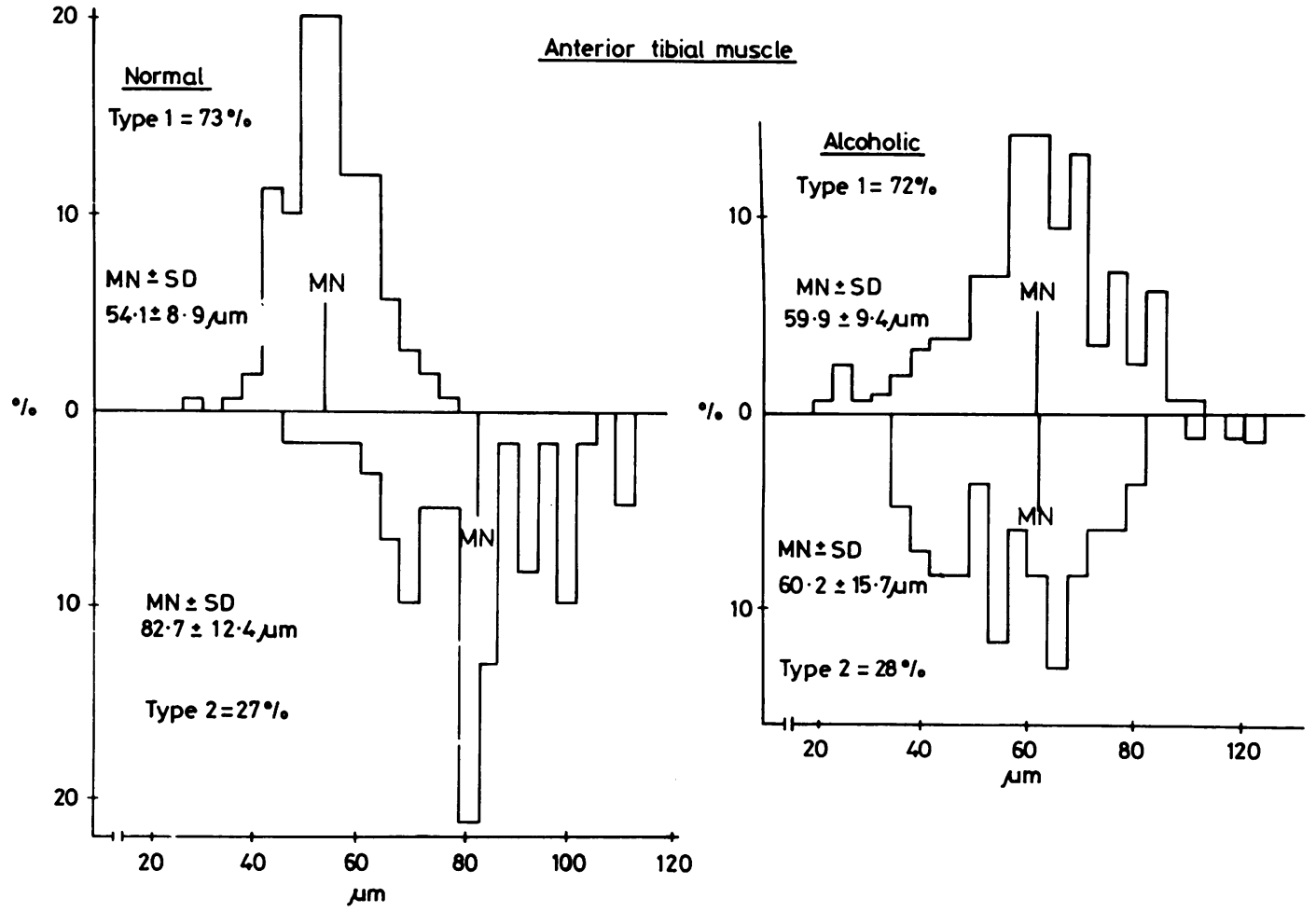

Fig 2 Histogram of fibre diameters from the anterior tibial muscle in a normal (left) and an alcoholic (right). 
Table Mean fibre diameter and quotient (mean diameter of type 2 fibre divided by mean diameter of type 1 fibre) for six normal individuals and 13 alcoholics

\begin{tabular}{lll}
\hline $\begin{array}{l}\text { Anterior } \\
\text { tibial muscle }\end{array}$ & $\begin{array}{l}\text { Control group } \\
n=6\end{array}$ & $\begin{array}{l}\text { Chronic alcoholics } \\
n=13\end{array}$ \\
\hline $\begin{array}{l}\text { Mean diameter }(\mu \mathrm{m}) \\
\quad \begin{array}{l}\text { Type-2 fibre } \\
\text { Type-1 fibre }\end{array}\end{array}$ & $\begin{array}{l}79.8 \pm 9 \cdot 3 \\
53.4 \pm 8.9\end{array}$ & $\begin{array}{l}69 \cdot 7 \pm 7.9 \\
60.1 \pm 5 \cdot 3\end{array}$ \\
$\begin{array}{l}\text { Ratio: } \\
\text { Mean } \phi \text { type 2 }\end{array}$ & 1.49 & $1 \cdot 16$ \\
\hline Mean $\phi$ type 1 & & \\
\hline
\end{tabular}

diameter of type 1 fibre. The quotient was 1.49 in the control group of six normal persons and dropped to an average of 1.16 in the 13 alcoholics studied.

The main chain enzymes involved in glycogenolysis (PH), glycolysis (HIM, TPDH, LDH), $\beta$-oxidation of fatty acids (HAD), citrate cycle (MDH, CS), pentosephosphate shunt (6$\mathrm{PGDH})$, and acid phosphatase activity (APH)

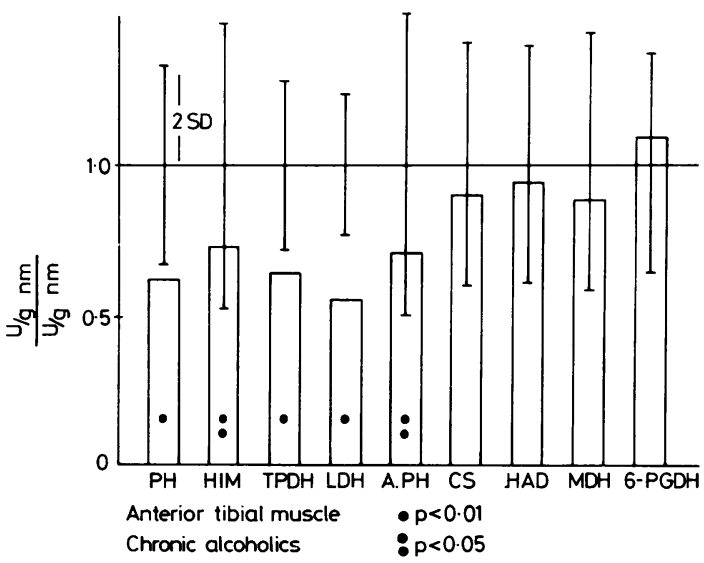

Fig 3 Mean enzyme activities of energy-supplying metabolism in 13 alcoholics (U/g p.m.) compared to healthy control group (U/g n.m.; $n=14$, range of normal $1 \cdot 0 \pm 2 \mathrm{SD})$.

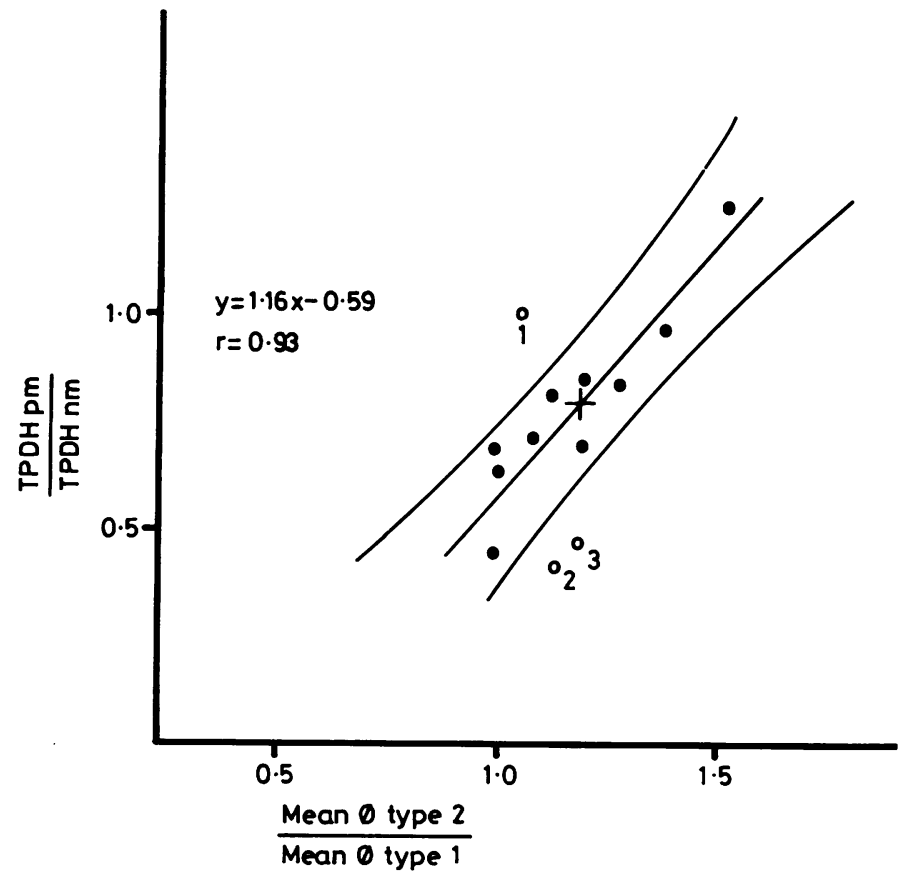

Fig 4 Dependency of biochemically determined TPDH activity on morphometrically determined mean diameter of type 1 and type 2 fibres in alcoholics $(n=13)$.

TPDH p.m. = TPDH activity in examined muscle of alcoholic,

TPDH n.m. = Mean TPDH activity of control group $(n=14)$,

- $=$ within range of tolerance,

$0 \quad=$ beyond range of tolerance,

$0=$ alcoholic after 6 months of abstinence,

$0_{2,3}=$ chronic alcoholics in poor physical condition with early cirrhosis of the liver 
measured in anterior tibial muscle specimens in alcoholics and 14 healthy persons of about the same age are shown in fig 3 for comparison. The activities of the glycolytic enzymes (PH, HIM, TPDH, LDH) and acid phosphatase (APH) were significantly lower, on the average, in the alcoholics than in the control group. The activities of the oxidative enzymes (CS, HAD, MDH) were not reduced. A linear relationship could be demonstrated between the change in glycolytic enzyme activity and the shift of the diameters of type 1 and type 2 fibres (fig 4). The quotients for TPDH activity in the anterior tibial muscles of the 13 alcoholics divided by the mean TPDH activity of the normal control group served as a criterion of glycolysis and were plotted on the ordinate of the diagram. These quotients were related to the quotients for the mean diameter of type 2 fibres divided by the mean diameter of type 1 fibres from the same muscle plotted at the abscissa. The correlation coefficient for 10 alcoholics was 0.93 . Three of the alcoholics could not be classified, since their values were well beyond the range of tolerance between the hyperbolas. In one case, the biopsy was taken after 6 months of abstinence: the biochemical changes had already normalised by this time (that is glycolytic TPDH activity had risen), but the morphologic alterations (that is type 2 atrophy or type 1 hypertrophy) were still pronounced. The other two patients were chronic alcoholics in poor physical condition with early cirrhosis of the liver. Glycolytic enzyme activities in the muscles of these patients were already markedly lowered; pronounced morphologic alterations (that is shift of diameter of fibre type) was not yet detectable.

\section{Discussion}

Our comparative electrophysiologic, histochemical, and biochemical study of the anterior tibial muscle in 13 chronic alcoholics indicated that the muscle wasting and decreased physical vitality in alcoholics are the result of neuropathy. Only those alcoholics with no clinically demonstrable signs of paresis, but with wasting of the distal and proximal muscles, were selected for the study. Eleven of the 13 patients complained of general muscle weakness. Ten patients showed clinical signs of sensory polyneuropathy in addition to muscle wasting. Electromyographic examination showed a discrete to mild axonal polyneuropathy in 11 patients. No pathologic findings were found in three patients on clinical examination and in two patients on electromyographic examination. Ten patients showed histochemical evidence of type 2 fibre atrophy. Angular fibres, target fibres, and type grouping of fibres indicating a chronic denervation process were often present. The discrete, degenerative fibre alterations suggested a concomitant myopathy. The shift of the mean diameter of type 2 fibres to the left and the slight increase of the mean diameter of type 1 fibres are best expressed by the quotient obtained by dividing the mean diameter of type 2 fibres by the mean diameter of type 1 fibres. This quotient dropped to 1.16 , on the average, in the alcoholics and was 1.49 in a control group of six normal individuals. The percentage of type 1 and type 2 fibres did not change.

Representative enzyme activities of the energysupplying metabolism determined in muscle specimens taken from the anterior tibial muscle of 13 alcoholics reflect the physiologic function ${ }^{13141618}$; shifts in the enzyme pattern are sensitive indicators of trophic muscle impairment. ${ }^{17}$ This is particularly true for glycolytic enzyme activity, which decreases in the very early stages of axonal nerve damage. Compared to the control group, the activity of the glycolytic and glycogenolytic enzymes (PH, HIM, TPDH, LDH) as well as acid phosphatase declined significantly in the alcoholics. No reduction in oxidative enzyme activities (CS, HAD, MDH) was detectable.

Kiessling and co the amount muscle in 11 alcoholics. This decrease was caused by $\bar{z}$ a reduction in size rather than in the number of fibres. A relationship between the reduction of $\frac{O}{3}$ glycolytic enzyme activity and the decrease of the $\overrightarrow{0} \overrightarrow{0}$ mean diameter of type 2 fibres or the increase of the mean diameter of type 1 fibres was also present in our alcoholics. Three alcoholic patients could not be classified, since their values were well beyond the calculated range of tolerance. The reason for this discrepancy between histochemical and biochemical findings may well be due to the following factors. The biopsy specimen in one patient was taken after 6 months of abstinence. The biochemical changes (that is rise of glycolytic enzymes) may have already normalised by the time of biopsy, whereas the morphologic alterations (that is, type 2 fibre atrophy) had not yet disappeared. The other patients were chronic alcoholics in poor physical conditions with early cirrhosis of the liver. Enzyme activities in the muscles of these patients may well have been considerably lower because of the catabolic metabolism; the histologic alterations, however, were not yet pronounced.

The morphologic alterations in the anterior tibial muscles of the alcoholics we examined were produced by a neuropathy. It is reasonable to assume that the metabolic disturbance in the axon resulted in early impairment of the energy-supplying 
metabolism of the muscle fibres. Sabri and coworkers ${ }^{25-27}$ assumed that many distal axonopathies could be produced by neurotoxic inhibition of glycolytic enzymes. In the light of these findings, one explanation for the early fall of glycolytic enzymes in muscle tissue may well be impaired axonal transport caused by inhibition of glycolysis following chronic alcohol abuse. Type 2 fibre atrophy and mild type 1 hypertrophy develop later. Thereafter, the morphologic tissue pattern reveals marked neurogenic damage. Myopathic alterations did not predominate in our findings.

We assume that the clinically demonstrable atrophy in the proximal muscles of the extremities in our alcoholics can also be attributed primarily to axonal damage. In an earlier study, we established that the biochemical and electromyographic alterations in the anterior tibial muscle of the same alcoholic were more pronounced than in the brachial biceps. ${ }^{17}$ Even in the brachial biceps, however, glycolytic enzyme activity decreased, although only discrete signs of neuropathy were obtained with electromyography. Therefore we suggest that the same damaging mechanism operates in distal and proximal muscles. Other investigators have also assumed that the chronic wasting of the proximal muscles observed in alcoholics is due to a neuropathy rather than a myopathy. Rossouw and coworkers' examined 13 rhronic alcoholics with histologic methods and found indications of a neuropathy in the proximal muscles of the extremities. Histochemical studies showed selective type 2 atrophy with signs of neurogenic damage and reinnervation. According to the studies by Faris and coworkers ${ }^{78}$ the subclinical alcoholic myopathy of the proximal muscles is due to alcoholic neuropathy. Neurophysiologic studies in chronic alcoholics have also indicated that damage can be detected in the proximal parts of the peripheral nerves in the early stages of the disease. Guiheneuc and coworkers ${ }^{28}$ as well as D' Amour and coworkers $^{29}$ found reduced $\mathrm{H}$ reflex response amplitudes and delayed conduction velocities in alcoholics. Liberson and coworkers ${ }^{30}$ observed delayed stimulation latency in the superior gluteal nerve. In the light of these findings, neurogenic damage with muscle wasting and weakness apparently also develops in the proximal muscles.

Other authors assume a combination of distal neuropathy and proximal myopathy in chronic

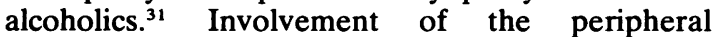
intramuscular nerves is also possible, ${ }^{5}$ but the electrophysiologic and histologic examination, in these cases, do not allow a clear cut decision for neuropathy nor myopathy. Further comparative histochemical and electrophysiologic examination of the proximal muscles of the extremities is planned to clarify the proximal muscle wasting and weakness.

We express our gratitude to Ms $\mathrm{H}$ Maute, Institute for Brain Research, and Ms M Kessler, Department of Neurology, for their technical assistance.

\section{References}

' Oh SJ. Chronic myopathy: an entity difficult to diagnose. South Med J 1972;65:449-52.

${ }^{2}$ Oh SJ. Alcoholic myopathy, electrophysiologic study. Electromyogr Clin Neurophysiol 1976;16:205-18.

${ }^{3}$ Ekbom K, Hed R, Kirstein L, Astrom KE. Muscular affections in chronic alcoholism. Arch Neurol 1964;10:449-58.

${ }^{4}$ Hed R, Lundmark C, Fahlgren H, Orell S. Acute muscular syndrome in chronic alcoholism. Acta Med Scand 1962;171:585-99.

${ }^{5}$ Lynch PG. Alcoholic myopathy. J Neurol Sci 1969; 9:449-62.

${ }^{6}$ Perkoff GT, Dioso MM, Bleisch V, Klinkerfuß G. A spectrum of myopathy associated with alcoholism. I. Clinical and laboratory features. Ann Int Med 1967;67:481-92.

' Faris AA, Reyes MG, Abrams BM. Subclinical alcoholic myopathy: electromyographic and biopsy study. Trans Am Neurol Assoc 1967;92:102-6.

${ }^{8}$ Faris AA, Reyes MG. Reappraisal of alcoholic myopathy. Clinical and biopsy study on chronic alcoholics without muscle weakness or wasting. J Neurol Neurosurg Psychiatry 1971;34:86-92.

9 Rossouw JE, Keeton RG, Hewlett RH. Chronic proximal weakness in alcoholics. $S$ Afr Med J 1976; 50:2095-8.

${ }^{10}$ Buchthal F. Einführung in die Elektromyographie. München: Urban und Schwarzenberg, 1958.

" Bass A, Brdiczka D, Eyer P, Hofer S, Pette D. Metabolic differentiation of distinct muscle types at the level of enzymatic organisation. Europ J Biochem 1969;10: 198-206.

${ }^{12}$ Bass A, Lusch G, Pette D. Postnatal differentiation of the enzyme activity pattern of energy-supplying metabolism in slow (red) and fast (white) muscles of chicken. Europ J Biochem 1970;13:289-92.

${ }^{13}$ Gollnick PD, Sjødin B, Karlsson J, Jansson E, Saltin B. Human soleus muscle-A comparison of fiber composition and enzyme activities with other leg muscles. Pftüger's Arch ges Physiol 1974;348:247-55.

${ }^{14}$ Green HJ, Daub B, Houston ME, Thomson JA, Fraser I, Ranney D. Human vastus lateralis and gastrocnemius muscles. A comparative histochemical and biochemical analysis. J Neurol Sci 1981;52:201-10.

${ }^{15}$ Kiessling KH, Pilstroem L, Bylund AC, Piehl K, Saltin B. Effects of chronic ethanol abuse on structure and enzyme activities of skeletal muscle in man. Scand $J$ Clin Lab Invest 1975;35:601-7.

${ }^{16}$ Langohr HD, Langohr U, Dieterich K, Janzik HH, Mayer K. Repräsentative Enzyme des energieliefern- 
den Stoffwechsels im normalen und denervierten M.biceps brachii, $\mathbf{M}$. deltoideus und $\mathbf{M}$. tibialis anterior des Menschen. J Neurol 1975;209:255-70.

${ }^{17}$ Langohr HD, Schumm F, Luithle HJ, Mayer K, Rentschler R.Vergleichende biochemische und elektrophysiologische Untersuchungen in der Skeletmuskulatur bei Alkoholismus. Arch Psychiat Nervenkr 1977;223:249-63.

${ }^{18}$ Pette D, Staudte HW. Differences between red and white muscles. In: Keul J, ed. Limiting factors of physical performance. Stuttgart: Thieme, 1973.

${ }^{19}$ Bücher T, Luh W, Pette D. Einfache und zusammengesetzte optische Tests mit Pyridinnucleotiden. In: Hoppe-Seyler, Thierfelder, eds. Handbuch $f$. Physiol. Chemie, Bd.VI/A, p. 292. Heidelberg: Springer, 1964.

${ }^{20}$ Dubowitz V, Brooke MH (eds.): Muscle biopsy: $A$ modern approach. London: WB Saunders Co Ltd, 1973.

${ }^{21}$ Brenni G, Jerusalem F, Schiller H. Myopathologie chronischer Denervationrozesse. Nervenarzt 1981;52: 692-702.

${ }^{22}$ Brooke MH, Engel WK. The histographic analysis of human muscle biopsies with regard to fiber types. 2. Diseases of the upper and lower motor neuron. Neurology (Minneap) 1969;19:378-93.

${ }^{23}$ Brooke MH, Engel WK. The histographic analysis of human muscle biopsies with regard to fiber types. 1 . Adult male and female. Neurology (Minneap) 1969;19:221-33.
24 Jerusalem F. (ed.). Muskelerkrankungen. Klinik, Therapie Pathologie. Stuttgart: Thieme, 1979.

${ }^{25}$ Sabri MI, Ochs S. Inhibition of glyceraldehyde-3phosphate dehydrogenase in mammalian nerve by iodoacetic acid. J Neurochem 1971;18:1509-14.

${ }^{26}$ Sabri MI, Moore CL, Spencer PS. Studies on the biochemical basis of distal axonopathies. I. Inhibition of glycolysis by neurotoxic hexacarbon compounds. J Neurochem 1979;32:683-9.

${ }^{27}$ Spencer PS, Sabri MI, Schaumburg HH, Moore CL. Does a defect of energy metabolism in the nerve fibre underlie axonal degeneration in polyneuropathies? Ann Neurol 1979;5:501-7.

${ }^{28}$ Guiheneuc P, Bathien N. Two patterns of results in polyneuropathies investigated with the $\mathrm{H}$ reflex. Correlation between proximal and distal conduction velocities. 1976;30:83-94.

${ }^{29}$ D' Amour ML, Shahani BT, Young RR, Bird KT. The importance of studying sural nerve conduction and late response in the evaluation of alcoholic subjects. Neurology (Minneap) 1979;29:1600-4.

${ }^{30}$ Liberson WT, Chong YC, Fried P. EMG studies in alcoholism. II. Terminal latencies in the superior gluteal nerve compared to those in distal peroneal and tibial nerves. Electromyogr Clin Neurophysiol 1979;19:15-26.

${ }^{31}$ Krause KH, Schmitt HP, Berlit P. Über die Kombination von alkoholischer Polyneuropathie und $\overline{0}$ Myopathie. Klinische, elektromyographische und $\underset{\mathbb{D}}{\infty}$ bioptische Befunde. Nervenarzt 1981;52:723-31. 